\title{
O CURSO DE PEDAGOGIA A PARTIR DOS DISCURSOS DE FUTUROS PEDAGOGOS: CONTRADIÇÕES, DESAFIOS E POSSIBILIDADES*
}

\author{
Bruna Pereira Alves, \\ da Universidade Federal de Santa Maria, Rio Grande do Sul \\ LiLIana Soares Ferreira, \\ da Universidade Federal de Santa Maria, Rio Grande do Sul
}

\begin{abstract}
Resumo: Apresenta-se, neste artigo, uma pesquisa com acadêmicos do $8 .^{\circ}$ semestre do Curso de Pedagogia de uma Universidade do Rio Grande do Sul, objetivando problematizar aspectos relativos ao Curso de Pedagogia, aos conhecimentos produzidos e ao trabalho dos pedagogos, com base nos discursos de acadêmicos entrevistados. A pesquisa, de cunho qualitativo, segue um amplo Estudo de Caso, em que foram realizadas entrevistas e análise documental do Projeto Pedagógico do Curso de Pedagogia da instituição em que os acadêmicos estudavam. Discutindo a Pedagogia como ciência e diferenciando o professor do Pedagogo, percebeu-se que os componentes curriculares, as mudanças no currículo e algumas lacunas são destacadas pelos estudantes como elementos determinantes em seu futuro trabalho e profissão.
\end{abstract}

Palavras-chave: Curso de Pedagogia. Professores. Pedagogos. Trabalho.

INTRODUÇÃO

Neste artigo, sistematiza-se investigação realizada com estudantes do Curso de Pedagogia, parte de uma pesquisa maior sobre o trabalho dos pedagogos na escola e o Curso de Pedagogia. A análise apresentada buscou problematizar aspectos relativos ao Curso de Pedagogia, aos conhecimentos

\footnotetext{
* Artigo recebido em 10/9/2010 e aprovado em 6/6/2011.
} 
produzidos e ao trabalho dos pedagogos, com base nos discursos de acadêmicos de uma Universidade Federal do interior do Rio Grande do Sul.

A pesquisa foi planejada e desenvolvida a partir da participação em grupos de pesquisa e projetos, em que se investigava sobre o trabalho, tendo como referência o Curso de Pedagogia e a escola. Além disso, uma das motivações para que a pesquisa acontecesse foi o diálogo com acadêmicos(as) que estavam cursando o último semestre do Curso de Pedagogia e suas manifestações de insegurança em relação ao estágio e ao seu trabalho futuro devido a lacunas percebidas durante a realização do Curso. Assim, considerando as experiências em um Curso de Licenciatura em Pedagogia e pesquisas realizadas sobre o trabalho dos professores, partiu-se da seguinte problematização: como os(as) acadêmicos(as) do $8 .^{\circ}$ semestre de uma Universidade Federal do interior do Rio Grande do Sul, em seus discursos, relacionam os conhecimentos produzidos no Curso de Pedagogia ao seu trabalho futuro como professores?

Importante destacar, desde já, que a concepção de Curso de Pedagogia e a concepção de Pedagogia são diferenciadas. O Curso de Pedagogia é uma proposta de viabilização de uma crença ou de uma perspectiva teórica referente à Pedagogia. Como pesquisadoras, acredita-se que a Pedagogia é a ciência da educação, cujo estudo central é referente a esse fenômeno social, político e cultural: a educação. Uma ciência dialógica, em acordo com a contemporaneidade, que permite, através da linguagem, que se possa adentrar no fenômeno educacional. Portanto, é uma concepção bastante ampliada de Pedagogia, cuja síntese visa a recompor essa área do conhecimento, para além da falta de clareza conceitual com que tem sido tratada, sempre que é reduzida somente a um curso para que os professores aprendam metodologias e didáticas a serem utilizadas em aula. Entretanto, considera-se que a Didática e a Metodologia são duas áreas que integram a Pedagogia e a ela se referem, mas não a substituem em sua abrangência.

Com base nesses pressupostos, apresenta-se, a seguir, a análise do resultado da pesquisa que entrelaça as respostas de acadêmicos do Curso de Pedagogia, em 2008, entendidos como um grupo representante dos pedagogos nesse contexto educacional e, portanto, social e cultural, sobre o trabalho deles como futuros professores e sobre os conhecimentos que produziram durante o Curso.

\section{Procedimentos metodolóGicos}

Na busca por respostas para a problematização elaborada para este trabalho utilizou-se uma abordagem qualitativa, refletindo sobre os dados 
coletados de forma a considerar e questionar hipóteses sobre os motivos pelos quais se chegou a tal resultado, relacionando-os, ainda, aos sujeitos da pesquisa e aos contextos escolares. Assim, pensando neste tipo de abordagem, encontra-se em Chizzotti (2006) uma caracterização semelhante ao que se pensa sobre pesquisa qualitativa:

O conhecimento não se reduz a um rol de dados isolados, conectados por uma teoria explicativa; o sujeito-observador é parte integrante do processo de conhecimento e interpreta os fenômenos, atribuindo-lhes um significado. O objeto não é um dado isolado e neutro; está possuído de significados e relações [...]. (CHIZZOTTI, 2006, p. 19)

É possível perceber, com esta afirmação de Chizzotti (2006), a importância de se por em relevo os sujeitos da pesquisa e não somente os dados obtidos, considerando, ainda, o contexto em que os entrevistados vivenciam a experiência relatada. Não é que os contextos determinem os sujeitos, mas estes se autoconstituem em decorrência de suas vivências e das interações que estabelecem.

Como procedimento metodológico, trata-se de um Estudo de Caso, entendendo-o como modo de pesquisa sobre o fenômeno em seu contexto real. Para a coleta de dados, foram realizadas entrevistas semiestruturadas, sendo organizadas previamente algumas questões que poderiam ser reformuladas ou complementadas no decorrer das entrevistas. Para tal, escolheram-se algumas categorias (trabalho dos professores, Curso de Pedagogia e conhecimentos) para a formulação das perguntas e a realização da análise posterior. É relevante destacar que todas as entrevistas foram gravadas e transcritas, de modo que informações importantes não se perdessem e que se mantivessem com o maior rigor possível a veracidade e os sentidos das respostas dadas a cada pergunta.

Além das entrevistas, realizou-se uma análise documental do Projeto Pedagógico do curso em que os entrevistados estudavam, com o objetivo de enriquecer a pesquisa e entender a relação entre o que está escrito neste documento e o que é exposto pelos acadêmicos nos discursos coletados. Também, durante esse procedimento, foram estabelecidas categorias a priori, as mesmas utilizadas para a entrevista, pautando-se por um rigoroso processo de leitura e análise, com uso de tabelas, contendo descritores de sentidos sobre o tema e a relação com as referências.

Os oito sujeitos interlocutores da pesquisa cursavam o $8^{\circ}$ semestre do Curso de Pedagogia diurno, e já estavam frequentando as instituições escolares em turmas de Educação Infantil e Anos Iniciais como estagiários, 
ou seja, vivenciando, embora não institucionalmente reconhecidos como tal, o trabalho de pedagogos-professores em contextos reais de escola. Tal vivência permite experimentar o cotidiano de trabalho, mesmo que ainda não estejam atuando como profissionais efetivos da escola. É nesse processo de simulação em tempo e contextos reais, os estágios, que os futuros pedagogos vivenciam a profissão.

Portanto, seguindo o caminho metodológico aqui relatado pretendeu-se efetivar a pesquisa de modo a alcançar os objetivos propostos, refletir sobre a problematização e apresentar considerações sobre o tema em questão, como "achados" da pesquisa.

\section{CURSO DE PEDAGOGIA: UM POUCO DE SUA HISTÓRIA}

Para uma maior compreensão do contexto educacional em que os estudantes entrevistados estavam inseridos, relata-se alguns fatos sobre a história do Curso de Pedagogia no Brasil e, posteriormente, na universidade pesquisada.

O Curso de Pedagogia no Brasil "foi instituído em 4 de abril de 1939" (SILVA, 2006, p. 11). Nessa época, vivia-se sob os impactos do movimento escolanovista e a necessidade de garantir maiores espaços para o estudo e a constituição das condições de trabalho dos professores, em sua maioria, leigos. Esse impacto contribuiu para que o Curso sofresse as influências das lutas por gratuidade, laicidade e obrigatoriedade da Educação Básica. Para alcançar tais objeitvos, fazia-se necessário que os professores fossem profissionais cujo trabalho contribuisse para o alcance desses objetivos. Cabe lembrar também a influência dos projetos pedagógicos das escolas ligadas às congregações religiosas, mantenedoras da maior parte dos cursos denominados Curso Normal, cuja estrutura e proposta estão na gênese dos cursos de Pedagogia.

Desde sua criação o curso era muito frágil, apresentando muitos problemas principalmente em relação às funções exercidas por bacharéis e licenciados. Para tentar amenizar a difícil situação vivenciada no curso de Pedagogia foi elaborado o parecer CFE n. 252/69, "que pretendia reformular as disciplinas e a estrutura curricular do curso" (SILVA, 2006, p. 19). Com o parecer percebe-se uma mudança significativa do ano de 1962 para o ano de 1969. Segundo Silva (2006),

a partir de 1962 o pedagogo era identificado como um profissional que personifica a redução da educação à sua dimensão técnica - o técnico de educação -, o currículo previsto para formá-lo era de cunho predominantemente generalista. Em 1969, consegue-se recuperar a educação em seu 
sentido integral na figura do especialista da educação, porém, sua formação nessa direção fica inviabilizada pelo caráter fragmentado da organização curricular proposta. (SILVA, 2006, p. 53-54)

Mesmo com algumas melhoras, em 1969 o Curso ainda estava enfraquecido e com muitas lacunas em sua organização curricular, e assim permaneceu por duas décadas. Em 1983 foi criado o Documento Final: "uma proposta de reformulação dos cursos de pedagogia e licenciatura" (SILVA, 2006, p. 68), que fortaleceu a idéia de Pedagogia como curso. Apesar disso, ainda existiam dúvidas quanto ao profissional a ser formado e à estrutura do curso para tal formação. Continuaram as tentativas de melhorar o curso de Pedagogia para que se compreendesse melhor qual seria efetivamente a função do pedagogo. Depois de 1998, enfim, se chegou a uma descrição mais clara do pedagogo, definido pela Comissão de Especialistas de Ensino de Pedagogia, da Secretaria de Educação Superior do Ministério de Educação, de acordo com Silva (2006), como o profissional para "atuar no ensino, na organização e gestão de sistemas, unidades e projetos educacionais e na produção e difusão do conhecimento, em diversas áreas da educação, tendo a docência como base obrigatória de sua formação e identidade profissionais" (SILVA, 2006, p. 82).

A caracterização de 1998 aproximou-se muito do pedagogo que se conhece hoje, evidenciando a docência como base do trabalho, mas destacando que seu trabalho também acontece na organização, gestão e produção em diversas áreas da educação. A docência tida como base para o trabalho do pedagogo é evidenciada nas Diretrizes Curriculares Nacionais para o Curso de Pedagogia e nos Projetos Pedagógicos de muitos cursos de Pedagogia no país.

Perecebe-se que, desde sua criação até os dias atuais, aconteceram muitas mudanças buscando melhorias para o curso. Algumas dessas alterações foram: quanto ao seu currículo, ao trabalho dos professores, à sua função, quanto às disciplinas que ofereceria, ao campo de trabalho, a ser restrito como espaço educativo ou não (SILVA, 2006). Estas dificuldades refletem-se até hoje em diversas universidades, mas, apesar disso, o curso vem se expandindo, até porque é considerado um curso de menor custo de manutenção. Nesse processo, os projetos pedagógicos vão se modificando aos poucos, tentando organizar-se de forma a contribuir efetivamente para a educação. Um dos grandes questionamentos feitos ao Curso é quanto ao seu objeto de estudo: é a educação? É a produção da aula? É a infância? Essa falta de clareza tem gerado vários debates entre os que defendem o curso como uma licenciatura que habilita professores para os anos iniciais do Ensino 
Fundamental e os que o defendem como núcleo da ciência ou das ciências da educação.

O CURSO DE PEDAGOGIA: O QUE SE DEPREENDE DOS DISCURSOS E DO PROJETO PEDAGÓGICO

O Curso de Pedagogia da Universidade em que a pesquisa aconteceu formou sua primeira turma de pedagogos(as) no ano de 1987. Atualmente, tem como objetivo geral:

formar professores/profissionais em nível superior para a docência da Educação Infantil e dos Anos Iniciais do Ensino Fundamental, capacitados para atuar nas diferentes modalidades de ensino e/ou nas demais áreas nos quais sejam previstos conhecimentos pedagógicos. (PP CURSO DE PEDAGOGIA, 2007)

O Projeto Pedagógico do Curso de Pedagogia destaca, ainda, a importância de ser esse profissional, o professor, "um pesquisador da sua prática pedagógica, que pode ser desenvolvida em vários âmbitos da Educação Básica, tanto em espaços escolares, quanto não escolares" (PP CURSO DE PEDAGOGIA, 2007). Acredita-se que, com a mudança ocorrida no PP do Curso, em que o Curso de Pedagogia Educação Infantil e o Curso de Pedagogia Anos Iniciais passaram a integrar o Curso de Pedagogia Licenciatura Plena, pretendeu-se ampliar o campo de trabalho dos pedagogos, mas continuou-se a enfatizar apenas o pedagogo como professor de Anos Iniciais, Educação Infantil e EJA, esquecendo-se que o pedagogo não é somente professor. Ao mesmo tempo, percebe-se que essa docência, enfatizada primeiramente pelos objetivos do Curso, é amenizada com a afirmação de que a ação pedagógica pode ser desenvolvida em vários âmbitos, tanto em espaços escolares quanto não escolares; mesmo assim, o documento não faz menção a como isso poderia acontecer.

Os egressos das novas turmas da Licenciatura Plena estariam em condições de trabalhar na Educação Infantil, nos Anos Iniciais do Ensino Fundamental, inclusive na modalidade de EJA - Educação de Jovens e Adultos e nas demais áreas nas quais fossem previstos conhecimentos pedagógicos. Esta mudança foi assim interpretada por um dos acadêmicos:

[...] eu entrei no Curso [...] como Educação Infantil, [...] então, na educação infantil, até o $4^{\circ}$ semestre eu tive a formação para isso [...] Eu vejo uma bagagem teórica muito mais voltada para educação infantil, e hoje eu avalio o curso de Pedagogia de uma forma muito negativa porque com toda essa mudança curricular os alunos foram muito prejudicados: eram muitas cadeiras em um semestre, [...] eu vi que toda essa mudança curricular no curso 
de Pedagogia ocasionou que muitos conhecimentos foram nos passado em vão, muitas cadeiras você teve no papel, mas, na realidade, não teve um certo conhecimento daquela disciplina. (ACADÊMICA F)

Realmente, abrem-se grandes oportunidades quando se amplia o campo em que o profissional trabalhará, porém, para que a mudança seja bem-sucedida, é necessário que os estudantes não sejam sobrecarregados e não tenham componentes curriculares deficitários, que não abordam suficientemente o que propõem. As mudanças podem e devem acontecer, mas não devem prejudicar o processo pedagógico na escola. No caso, os pedagogos em processo de formação estão se sentindo inseguros para trabalharem nas diferentes áreas para as quais estão sendo "preparados".

Retomando o objetivo estabelecido pelo Curso, principalmente no que se refere a permitir que os acadêmicos atuem nas diferentes modalidades de ensino, percebe-se a distância entre o que está escrito no PP e o vivenciado pelos acadêmicos, já que a maioria dos entrevistados(as) afirma haver muitas lacunas também em relação às demais modalidades, que deveriam ser bem trabalhadas já que estão previstas no objetivo geral do Curso.

[...] considerando que eu entrei numa licenciatura e saí com duas licenciaturas [referência à junção entre as duas propostas de licenciaturas que existiam até 2006], eu acredito que ficaram muitas lacunas em função da gente não ter tido algumas disciplinas que as séries iniciais tiveram e as do EJA também. $E$ isso se refletiu em nosso estágio, porém não foi determinante, mas a gente percebeu que faltou algum embasamento teórico. (ACADÊMICA H)

Segundo Silva (2006), o problema fundamental do Curso de Pedagogia no Brasil está relacionado à "dificuldade em se definir a função do curso e, consequentemente, o destino de seus egressos" (SILVA, 2006, p. 49). Esta também é uma deficiência do Curso de Pedagogia citada por uma das entrevistadas: "Eu acredito que o curso de Pedagogia tem algumas lacunas desde a existência dele, desde que ele foi criado [...] e isso prejudica a formação [...]" (ACADÊMICA C).

Percebe-se que muitas das dificuldades enfrentadas pelo curso de Pedagogia no Brasil refletem-se em cursos de Pedagogia como o da Universidade em que os entrevistados estudavam. Com base nas considerações até então descritas serão apresentadas análises dos discursos dos acadêmicos-entrevistados.

Fazendo um panorama geral da pesquisa foi possível perceber que os acadêmicos entrevistados remetem, geralmente, às lacunas que acreditam ter ficado no decorrer de seus estudos. Os componentes curriculares 
relacionados às metodologias, geralmente, são os mais apontados como contendo lacunas, já que, de acordo com as entrevistas realizadas, se espera o Curso todo por eles, pensando encontrar uma base maior para enfrentar as dificuldades de seu trabalho futuro. Esta é a percepção dos entrevistados: o Curso de Pedagogia como espaço de produção de conhecimento sobre o trabalho dos pedagogos como professor.

De acordo com os sujeitos da pesquisa, o constituir-se Pedagoga(o) remete à noção de um profissional prático, reduzindo o curso somente aos componentes curriculares de metodologia e ao estágio. Ou seja, há uma expectativa em se aprender como lidar, o que fazer e quando, para, nas situações futuras, em aula, poder agir de modo a alcançar os objetivos relativos à produção do conhecimento, sem pensar ou considerar que o trabalho dos pedagogos vai além da sala de aula. Nos discursos em questão o Curso foi analisado como caracterizado por:

a) lacunas nas metodologias: "quando a gente começa a entrar nas metodologias que você está esperando, não que eles digam o que você tem que fazer assim, mas que digam: 'isso você trabalha na 2. a série, isso na $3 .^{a}$ série pode ser trabalhado', e ninguém diz nada" (ACADÊMICA A). Percebe-se que os estudantes não querem receitas prontas no Curso de Pedagogia, mas que os professores do Curso aprofundem melhor os componentes curriculares referentes às metodologias, de modo que eles possam ajudar no estágio.

Sobre esta preocupação excessiva dos estudantes em relação à metodologia é interessante considerar que Pedagogia, metodologia e didática são coisas diferentes. Sucintamente pode-se afirmar que Pedagogia é a ciência; metodologia é uma escolha cotidiana feita por quem pensa um ato pedagógico; e didática é a ação pedagógica em si, seu modus operandi e as concepções que o subsidiam. Isto posto, percebe-se que didática e metodologia são integrantes da Pedagogia, e esta é responsável por pensar e propor didáticas e metodologias em conformidade com as teorias e pressupostos da educação.

b) muitas lacunas na formação de um professor para crianças: "eu acho que existem muitas lacunas pra se formar um professor para crianças no Curso de Pedagogia, porque ele não é entendido ainda como um curso que forma professores essencialmente" (ACADÊMICA C). Percebe-se, com esta afirmação, que alguns acadêmicos acreditam que o trabalho do pedagogo é apenas ser professor. Um pedagogo pode ser professor, como destacado anteriormente, mas seu trabalho não é somente esse. $O$ trabalho dos pedagogos compreende também a gestão em suas diferentes fases, incluindo o pensar pedagógico. Todavia, é necessário refletir com mais atenção sobre o pedagogo como 
professor, já que grande quantidade de pedagogos vão para as escolas trabalhar com turmas de Educação Infantil e Anos Iniciais como professores. Até que ponto não querer trabalhar como professor, mas acabar trabalhando como professor vai interferir para que se produza a aula, o trabalho? Será que não é um pouco desse "não querer mas trabalhar assim mesmo" que se vê refletido em muitas escolas? Desse modo, apesar de o Projeto Pedagógico do Curso intencionar prioritariamente a formação de professores, será que é essa a expectativa dos acadêmicos? Talvez fosse significativo conhecer a Pedagogia de modo mais ampliado, para além da proposta de formar professores do início do processo de alfabetização, mas contemplando as diferentes áreas em que pode acontecer a atuação dos pedagogos. Desse modo, os acadêmicos teriam a oportunidade de elaborar uma diferenciação entre o trabalho do pedagogo da sala de aula e o do pedagogo da escola (MARQUES, 1996).

c) distância entre teoria e prática: ouve-se muito falar em práxis (teoria e prática associadas, juntas), entretanto esta não está sendo percebida pela maioria dos acadêmicos do Curso de Pedagogia que participaram da pesquisa. É o que afirma uma aluna:

eu vejo que eu tenho muito mais facilidade de trabalhar agora com as crianças nessas áreas que a gente teve exemplos e a gente construiu coisas aqui e não ficou só o papel. Que muitas disciplinas da metodologia foi só nós elaborarmos planos de trabalhos, planos de aula sem desenvolvê-los, sem implementar e, daí [...], a gente ficava imaginando alunos, imaginando como seria uma aula. (ACADÊMICA D)

Qual a relevância de não apenas falar da união teoria e prática, mas fazer com que esta união realmente se faça presente em um Curso de Licenciatura? A práxis, tambem, é o modo como os sujeitos podem se inserir em determinado processo, vivenciando-o efetivamente, sem rupturas. Trabalhar na perspectiva da práxis pedagógica pode-se constituir em um encaminhamento epistemológico que poderia garantir que os pedagogos entendessem a educação não como um fazer ou como um pensar dissociados. Quem sabe assim se poderia dirimir a conhecida fragmentação que a escola promove entre a ação e a reflexão.

d) ajudou no todo da formação acadêmica: os entrevistados acrescentam, na maioria das respostas, que o Curso de Pedagogia ajudou muito, pois não poderiam ser professores ou ter chegado ao lugar em que chegaram sem o Curso. Além disso, acrescentam ainda que os demais recursos e as condições ofertadas pelo Curso para pesquisa, participação em eventos, atividades culturais, em geral, ajudam a complementar a formação acadêmica: 
[...] minha formação acadêmica no todo me ajuda, não só dentro da sala de aula, nas aulas, mas principalmente na participação em projetos de pesquisa, participação em todos os espaços da universidade, nas discussões que existem em eventos, isso sim, esse conjunto me ajuda. (ACADÊMICA C)

É verdade que a participação em eventos, grupos e projetos de pesquisa enriquecem e ajudam o estudante a entender melhor sobre assuntos discutidos ou não em sala de aula. Porém, é necessário lembrar que o Curso ocupa os horários vespertinos e, algumas vezes, parte do noturno, restando apenas as manhãs para que os estudantes participem de todas estas atividades.

Esses foram os aspectos destacados nos discursos dos acadêmicos entrevistados. Considerando os quatro itens descritos, percebe-se que, para eles, as metodologias e o estágio são fundamentais para seu futuro trabalho, já que defendem o pedagogo apenas como professor. Em relação a isto, acredita-se ser importante um aprofundamento maior no que diz respeito ao trabalho como professor, além de uma ampliação desta concepção para que os estudantes percebam as possibilidades de trabalho além da sala de aula.

Assim, tendo em vista as análises até agora apresentadas, percebe-se que os acadêmicos reconhecem que o Curso de Pedagogia Ihes auxiliou e foi proveitoso, mas evidencia-se claramente a preocupação destes com o estágio, com o trabalho, com o "dar aulas", com o como agir na sala de aula, muito mais do que com qualquer outra questão referente à educação, à produção do conhecimento. Por mais que os(as) acadêmicos(as) não peçam diretamente receitas sobre o que fazer nas aulas, sentem necessidade de serem melhor direcionados e esclarecidos em relação a estas questões.

\section{RELACIONANDO OS DADOS DE PESQUISA E APORTES TEÓRICOS}

Durante toda a pesquisa foi considerado que os cursos de Pedagogia precisam se constituir como um espaço e um tempo para a inserção do aluno no campo educacional, não somente como futuros professores, mas como teóricos da educação. Partilha-se a compreensão de que a Pedagogia é a ciência da educação, posto que permite compreender o fenômeno educacional e propor alternativas para a educação nos diferentes espaços sociais. Trata-se da ciência que produz teoria sobre educação: "uma teoria da prática: a teoria da prática educativa" (SAVIANI, 2006, p. 1). Porém, cabe alertar que, "se toda pedagogia é teoria da educação, nem toda teoria da educação é pedagogia. Na verdade o conceito de pedagogia se reporta a uma teoria que se estrutura a partir e em função da prática educativa" (SAVIANI, 2006, 
p. 1). E o autor explica: "não se constituem como pedagogia aquelas teorias que analisam a educação pelo aspecto de sua relação com a sociedade não tendo como objetivo formular diretrizes que orientem a atividade educativa" (SAVIANI, 2006, p. 1). Faz-se necessário reconstituir essa concepção, ou, com Saviani, passar do senso comum à consciência filosófica, o que significa "passar de uma concepção fragmentária, incoerente, desarticulada, implícita, degradada, mecânica, passiva, simplista a uma concepção unitária, coerente, articulada, explícita, original, intencional, ativa e cultivada" (SAVIANI, 1980, p. 5). Obviamente, esse é um trabalho de pedagogos organizados em grupos, coletivamente articulados, posto que implica rever a teoria em ação dessa ciência. E considerar o que afirma Vázquez: "A teoria em si não transforma o mundo. Pode contribuir para sua transformação, mas para isto tem que sair de si mesma, e, em primeiro lugar, tem que ser assimilada pelos que vão ocasionar, com seus atos reais, efetivos, tal transformação" (VAZQUEZ, 1977, p. 206). Do mesmo modo, a teoria pedagógica em si não transforma a educação, é necessária a ação dos sujeitos.

Tanto os discursos dos entrevistados como o próprio Projeto Pedagógico do Curso pesquisado restringem a Pedagogia a uma licenciatura que habilita ao trabalho como professor. Mas a pedagogia é mais, é também a ação comprometida e responsável no sentido de contribuir para a educação de modo amplo, tanto na escola, como na Igreja, nas ONGs, no hospital, nas fábricas etc. "Pedagogia é, antes de tudo, um campo científico, não um curso" (LIBÂNEO, 2002, p. 60). E complementa, quanto ao campo de abrangência da Pedagogia: “Como toda educação corresponde a uma pedagogia, também há uma diversidade de trabalhos pedagógicos para além das atividades de educação escolar e ensino" (LIBÂNEO, 2002, p. 60).

Do mesmo modo, é significativo destacar que não há somente Pedagogia na escola, mas em todo o contexto social, considerando-se também possibilidades mediadas pelas tecnologias, que geram ações pedagógicas em muitos outros espaços sociais ampliados. Ou seja, a Pedagogia é elemento cultural no sentido amplo, integra a cultura e é dela referente, além de contribuir para sua socialização. Portanto, pode-se afirmar que "o educativo (e o escolar) fazem parte de uma complexa engrenagem cultural e social" (SOLÀ, 1995, p. 215-216).

Em um contexto social cujos meios de comunicação, de modo geral, destacam estar ocorrendo uma crise da educação e da escola, e a justificam ressaltando as condições deficitárias em que se encontram as escolas, revelando os salários precários dos professores, noticiando os baixos índices nas avaliações realizadas pelo Estado, preocupa demasiadamente o 
descaso com que vem sendo tratada a educação e, em decorrência, todos os elementos atinentes à escola, ao conhecimento, ao currículo, às políticas públicas educacionais, à gestão da educação, e, sobretudo, à Pedagogia.

Nessa linha de raciocínio, professores e pedagogos são sujeitos constituídos de modo diferente. Pedagogos podem trabalhar como professores, porém, podem ir além da sala de aula, agindo também como cientistas educacionais. Parece comum chamar professores de anos de iniciais de pedagogos, entretanto, trata-se de um equívoco conceitual. O pedagogo trabalha com a educação de modo geral, como fenômeno independente da escola. Os professores trabalham em espaços de aula, formais ou informais. Talvez se possa afirmar que trabalhar como professor é uma condição que os pedagogos podem se permitir de modo bastante oportuno, tendo em vista os estudos que realizam. Porém, podem ir além. Não somente produzir a aula, mas teorizar sobre ela, propondo alternativas e modos de pensar o pedagógico. Nos discursos dos entrevistados e no PP do Curso, fica evidente essa restrição da Pedagogia e do pedagogo à produção da aula somente. Todavia, é preciso que se pense além, que se consiga ver o pedagogo como cientista da educação, como aquele que não somente produz a aula, mas participa e pensa sobre os demais processos educativos que ocorrem dentro e fora da instituição escolar.

O trabalho dos pedagogos não acontece somente na escola, mas é dentro dela, com o pedagogo como professor ou como pedagogo da escola, que se percebeu na pesquisa, com mais frequência, os problemas em relação a este trabalho, sendo comum apontar como possível causa de dificuldades no trabalho dos pedagogos os déficits em sua formação.

Parece consenso que os currículos de formação de professores baseados no modelo da racionalidade técnica mostram-se inadequados à realidade da prática profissional docente. As principais críticas atribuídas a esse modelo são a separação entre teoria e prática na preparação profissional, a prioridade dada à formação teórica em detrimento da formação prática e a concepção da prática como mero espaço de aplicação de conhecimentos teóricos, sem um estatuto epistemológico próprio. Um outro equívoco desse modelo consiste em acreditar que para ser bom professor basta o domínio da área do conhecimento específico que se vai ensinar. (PEREIRA, 1999, p. 112)

Embora os Cursos de Pedagogia tenham vivenciado diversas mudanças, esta afirmação continua válida. Se é enfatizado durante o curso a docência como base da formação do pedagogo, é preciso que essa base seja sólida. Em geral tem-se percebido que muitos acadêmicos saem da Universidade sem conseguir relacionar a teoria e a prática, apenas 
reproduzindo aulas de outros professores, sem conseguir compreender que podem, por si só, produzir uma aula em que os estudantes aprendam e produzam conhecimento. $O$ Curso de Pedagogia não fornece aos acadêmicos dicas sobre o que fazer na sala de aula, como fazer ou quando fazer, mas deveria preparar o acadêmico para buscar em si próprio estas respostas, oferecendo no decorrer do Curso uma base teórico-prática que Ihes possibilitasse entender que a aula dependerá deles, de sua metodologia, de sua organização e dos estudantes com quem trabalharão.

\section{CONSIDERAÇÕES FINAIS}

A investigação aqui relatada discutiu o Curso de Pedagogia de uma Universidade Federal do interior do Rio Grande do Sul e sua influência sobre o trabalho dos acadêmicos que estavam em estágio, como futuros professores.

No decorrer da análise foi possível perceber que os acadêmicos se sentiam inseguros à frente de uma sala de aula, pois não sabiam como agir em determinadas situações, o que falar ou fazer, atribuindo esta situação à distância entre teoria e prática, observada dentro do Curso.

Considerando este contexto, acredita-se que é interessante repensar a trajetória dos acadêmicos durante o Curso de Pedagogia, já que eles farão a diferença, determinarão, construirão ou desconstruirão, ajudarão ou prejudicarão inúmeros estudantes que passarem pelas escolas e salas de aula em que estarão trabalhando. Ressalta-se ainda que a necessidade de repensar a trajetória dos estudantes de Pedagogia remete não só ao Curso da Universidade pesquisada, mas também a outros Cursos de Pedagogia, que, no geral, embora sofram modificações curriculares frequentemente, alterando o ritmo e o aprendizado dos estudantes, ainda não conseguem fazer com que a práxis se evidencie durante todo o Curso, ou seja, ainda têm lacunas a serem superadas.

No decorrer do trabalho foi possível retomar fatos importantes da história do Curso de Pedagogia, que passou por diversas transformações devido às mudanças nas políticas públicas para a área, como as Diretrizes Curriculares de 2006. Os acadêmicos(as) entrevistados(as) também sofreram com as modificações que ocorreram durante sua trajetória no Curso. A mudança curricular que transformou o Curso de Pedagogia Licenciatura Plena fez com que os estudantes fossem sobrecarregados de tarefas e componentes curriculares, o que também os prejudicou segundo eles(elas), a mudança fez com que aparecessem mais lacunas. Além disso, a distância entre teoria e prática existente no Curso de Pedagogia evidenciou-se no discurso de 
alguns acadêmicos, que a consideravam causa do déficit no aprendizado e no trabalho dos estudantes.

Assim, considera-se urgente que, desde o ingresso dos acadêmicos no Curso de Pedagogia, os conhecimentos e os componentes curriculares sejam integrados com situações concretas que façam com que eles problematizem e procurem soluções. É necessário que o trabalho como princípio educativo, teórico e prático, e não como mera ação de trabalhar, permaneça durante todo o curso para que os estudantes possam formar seus próprios conceitos e convicções, possam conhecer desde cedo com quem irão trabalhar e quais as situações que poderão presenciar (LIBÂNEO; PIMENTA, 1999).

A pesquisa apresentada possibilitou problematizar a Pedagogia como ciência da educação e estabelecer diferenças entre o professor e o pedagogo, destacando pontos relevantes dessa discussão com base no discurso dos acadêmicos entrevistados. Além disso, ficou claro que os componentes curriculares, as mudanças no currículo e algumas lacunas do curso são destacadas pelos estudantes como elementos determinantes em sua futura profissão.

THE PEDAGOGY COURSE BASED ON THE DISCOURSE OF FUTURE TEACHERS: CONTRADICTIONS, CHALLENGES AND POSSIBILITIES

ABSTRACT: This article, which presents a survey of $8^{\text {th }}$ semester Pedagogy students at a University in Rio Grande do Sul, sets out to discuss aspects of the Pedagogy Course, the knowledge produced and the work of pedagogues, using as a basis the discourse of students who were interviewed. The research is of a qualitative nature, based on an extensive case study. Interviews were held and a documental analysis was made of the Pedagogical Project of the Pedagogy Course in the institution where the students studied. Pedagogy as a science was discussed as was what makes the pedagogue different from the teacher. It was observed, in this study, that the curriculum components, changes in the curriculum and lacunas were highlighted by the students as vital elements in their future work and profession.

KEYWORDS: Pedagogy Course. Teachers. Pedagogues. Work.

\section{REFERÊNCIAS}

CHIZZOTTI, A. Pesquisa em ciências humanas e sociais. 8. ed. São Paulo: Cortez, 2006.

LIBÂNEO, J. C.; PIMENTA, S. G. Formação de profissionais da educação: visão crítica e perspectiva de mudança. Educação e Sociedade: revista quadrimestral de Ciência da Educação. Centro de Estudos Educação e Sociedade (Cedes), n. 68, Campinas, v. XX, p. 239-277, 1999. 
LIBÂNEO, J. Ainda as perguntas: o que é pedagogia, quem é o pedagogo, o que deve ser o curso de Pedagogia. In: PIMENTA, S. G. (Org.). Pedagogia e pedagogos: caminhos e perspectivas. São Paulo: Cortez, 2002.

MARQUES, M. O. Educação, interlocução, aprendizagem reconstrução de saberes. ljuí: UNIJUÍ, 1996.

PEREIRA, J. E. D. As licenciaturas e as novas políticas educacionais para a formação docente. Educação e Sociedade: revista quadrimestral de Ciência da Educação. Centro de Estudos Educação e Sociedade (Cedes), n. 68, Campinas, v. XX, p. 109-125, 1999.

SAVIANI. D. Educação: do senso comum à consciência filosófica. São Paulo: Cortez, 1980.

SAVIANI. D. As concepções pedagógicas na História da Educação Brasileira. In: LOMBARDI, J. C; SAVIANI, D; NASCIMENTO, M. I. M. (Orgs.). Navegando pela História da Educação Brasileira. Campinas: Autores Associados/HISTEDBR, 2006.

SILVA, C. S. B. da. Curso de pedagogia no Brasil: história e identidade. 3. ed. Campinas, SP: Autores Associados, 2006.

SOLÀ, P. El estúdio diacrónico de los fenómenos educativos y las tendencias historiográficas actuales. In: Congreso Internacional História a Debate, Santiago de Compostela. Actas... Santiago de Compostela: Carlos Barros Editor, 1995. t. II, p. 213-220.

UNIVERSIDADE FEDERAL DE SANTA MARIA. Centro de Educação. Curso de Pedagogia Licenciatura Plena Diurno. Projeto Político-Pedagógico, 2007.

VAZQUEZ, A. D. Filosofia da práxis. Rio de Janeiro: Paz e Terra, 1977.

Bruna Pereira Alves: é acadêmica do curso de mestrado do Programa de Pós-Graduação em Educação da UFSM, na Linha de pesquisa LP2 Práticas Escolares e Políticas Públicas. Integrante do grupo de pesquisa KAIRÓS - Grupo de Estudos e Pesquisas sobre Trabalho, Políticas Públicas e Educação, é bolsista CAPES/DS.

E-mail: brualves_22@yahoo.com.br

Liliana Soares Ferreira: Doutora em Educação, Professora do Programa de Pós-Graduação UFSM. Atualmente, é professora do Departamento de Fundamentos da Educação, do Centro de Educação, na Universidade Federal de Santa Maria/RS, atuando na graduação, especialização e no Programa de Pós-graduação em Educação. É líder do grupo Kairós - Grupo de Estudos e Pesquisas sobre Trabalho, Educação e Políticas Públicas.

E-mail: anaililferreira@yahoo.com.br 